\title{
Design and Analysis of a Wind Turbine Blade with Dimples to Enhance the Efficiency through CFD with ANSYS R16.0
}

\author{
M. Rajaram Narayanan ${ }^{\mathrm{a}}$, S. Nallusamy, M. Ragesh Sathiyan \\ Department of Mechanical Engineering, Dr. M G R Educational and Research Institute, \\ Chennai-600095, Tamilnadu, India
}

\begin{abstract}
In the global scenario, wind turbines and their aerodynamics are always subjected to constant research for increasing their efficiency which converts the abundant wind energy into usable electrical energy. In this research, an attempt is made to increase the efficiency through the changes in surface topology of wind turbines through computational fluid dynamics. Dimples on the other hand are very efficient in reducing air drag as is it evident from the reduction of drag and increase in lift in golf balls. The predominant factors influencing the efficiency of the wind turbines are lift and drag which are to be maximized and minimized respectively. In this research, surface of turbine blades are integrated with dimples of various sizes and arrangements and are analyzed using computational fluid dynamics to obtain an optimum combination. The analysis result shows that there is an increase in power with about $15 \%$ increase in efficiency. Hence, integration of dimples on the surface of wind turbine blades has helped in increasing the overall efficiency of the wind turbine.
\end{abstract}

\section{Introduction}

In the modern scenario energy crisis and fossil fuel depletion has urged many countries to switch to other forms of renewable sources of energy. Among various forms of renewable energy, hydel and wind energy plays vital role in energy generation because of their surplus availability and higher efficiencies of energy transformation compared with tidal or solar. The amount of installed wind power is increasing every year and many nations have made plans to make large investments in wind power in the near future. High efficiency wind turbines are being designed on the chase of energy conversion and the analysis showed that the maximum extraction of energy possible from a turbine rotor is about $59 \%$ of the incoming kinetic energy [1-4]. The general public associates' wind turbines with horizontal axis wind turbines and are unaware of the several other technologies based on the vertical axis wind turbines which are less frequently used [5-8]. The energy absorbed from the wind is converted into mechanical energy by using wind turbines that is used to drive an electrical generator and then converted into electrical energy [9-13]. Based on our requirement airfoil blades are selected from the national renewable energy laboratory Sseries, thicker than the ones that are seen on airplanes and for the generation of about $1.5 \mathrm{MW}$ power at wind speeds of $12-20 \mathrm{~m} / \mathrm{s}$, the optimal blade was found to have a span of 40 meters [14-17]. The turbine blade is joined with the hub with the help of a cylindrical root section and blade profile is divided into three sections. Three different profiles such as S818, S825 and S826 are included in each section of the blade starting from the root. The blade was modelled with 3D CAD software and airfoils modelled with the point data which defines a particular airfoil with the blade dimensions including twist, chord length and span with respect to 40 meters blade length [18-21]. Earlier the scientists used to create scaled prototypes of the aerofoil to be analyzed and then place them in large wind tunnels to simulate the real world working conditions [22-25]. In modern times the process of testing and analysis has been highly computerized and is solved using computational fluid dynamics (CFD) [26-29]. The geometry of the problem here is the turbine blade which has to be analysed. The blade is modelled using the solid works modelling software and then imported to the CFD analysis software and a domain is created for the study which acts as a virtual boundary for the fluid [30-33]. The behaviour of a wind turbine rotor in a flow field may conveniently be analyzed by introducing the actuator disc principle [32-35]. The basic idea of the actuator disc principle in connection with rotor aerodynamic calculations is to replace the real rotor with a permeable disc of equivalent area where the forces from the blades are distributed on the circular disc. The basic assumption for a classical blade by element

\footnotetext{
${ }^{a}$ Corresponding author: drmrajaram@yahoo.com
} 
momentum method is the annual stream tubes are independent [36-39]. Thus by using this methodology along with the Reynolds averaged navier-stokes equations a near to actual result can be obtained.

\subsection{Dimples}

Dimples are small depressions on the surface which is usually permanent like in case of a golf ball. The presence of dimples increases the amount of energy and linear momentum that are available to those particles of fluid that move in a tiny region near to the surface of the ball called the boundary layer as shown in Figure 1. The existence and importance of the boundary layer are due to the peculiar behaviour of fluid friction near the surface of a solid body that is in relative motion with the surrounding fluid. In case of a golf ball, dimples trip air particles that are moving close to them. This disturbance causes the particles to jiggle sideways while they travel forward, instead of staying in lanes of traffic that are perfectly parallel to each other at all times, as expected in laminar flow. This jiggling forces particles in adjacent lanes to bump into each other, causing linear momentum to be transferred through bumping. When bumping is vigorous enough, its net result is that the bulk flow of air in the boundary layer becomes turbulent. Based on the above an attempt was made to increase the efficiency by changes in surface topology of wind turbine blades by CFD and ANSYS R 16.0.

\subsection{CFD Analysis}

Initially, CFD analysis was carried out without dimple done in order to find out the degree of accuracy to obtained results and match with the actual results and also to differentiate the efficiency between the blades with and without dimples. Blade alignment, domain dimensions, mesh settings and boundary conditions are considered to be the same for both the blades. Since the blades of the wind turbine are identical and are symmetrically arranged at angular gaps of 1200 , it is enough to analyse only one blade with a domain in the shape a sector having 1200 angle. The blade is positioned $1 \mathrm{~m}$ away from the axis of rotation to compensate for the hub. The wind speed considered for analysis is $12 \mathrm{~m} / \mathrm{s}$ with the blade rotating at the speed of 2.2 $\mathrm{rad} / \mathrm{sec}$ or $21 \mathrm{rpm}$. The relative motion between the blade tip and the flow stream results in a relative velocity which approaches the blade at an angle of 960 where as this angle is obtained by using the velocity vectors of the wind as well as the blade and then finding their resultant. Hence, the blade is also rotated in order to make its tip incline at the same angle. This causes the tip of the blade to have an almost zero angle of attack. Based on the actuator disc principle, a fluid domain is created for the wind turbine with dimensions of inlet face radius is $120 \mathrm{~m}$, inlet face distance from rotor is $90 \mathrm{~m}$, outlet face radius is $240 \mathrm{~m}$ and outlet face distance from rotor is $180 \mathrm{~m}$. The above mentioned radii are that of the sector which will cover only one blade, using the symmetric boundary condition the entire wind mill is analysed. The domain is created using the ANSYS R16.0 design modular software. The blade profile is then subtracted from the blade to create a void which acts as a virtual boundary. The speed of rotation is given as $2.2 \mathrm{rad} / \mathrm{s}$ which is the maximum speed with which the windmill will rotate in its optimum conditions with wind speeds of $12-20 \mathrm{~m} / \mathrm{s}$. K-omega equation model is chosen for the analysis and hybrid initialization carried out.

\section{Results and Discussion}

The plain blade was first analysed with the above mentioned settings and the following results were obtained. The pressure $(\mathrm{Pr})$ contour of the top side of the blade as shown in the Figure 2 shows the low pressure created at the top surface of the wind turbine blade. The pressure contour of the bottom side of the blade is shown in the Figure 3. The pressure developed at the bottom is significantly higher when compared to that of the top side of the blade which confirms that lift is generated. From Figure 4 it is clear that a high pressure is created at the bottom surface just near the leading edge of the blade and it creates a resistance to the rotation of the turbine and is otherwise known as drag. So, from this the position at which the drag force acts and is maximum visible. This data is then used to approximate a region where the dimples would be most effective and this region is found to be on the bottom face of the blade in the mid region near the trailing edge. Only the mid region is selected as the region near the root is too slow for drag to have a considerable effect and the region near tip is too fast for dimples to have any considerable effect hence dimples are designed and shown in Figure 5.

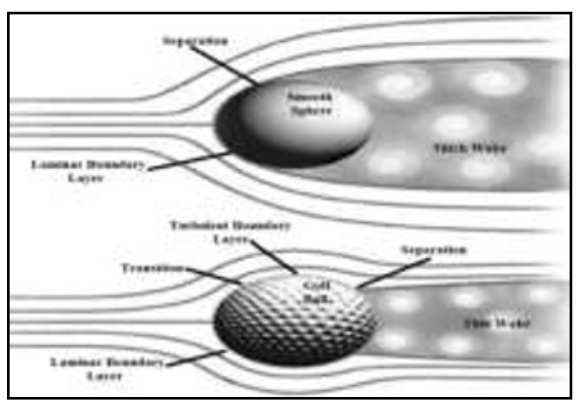

Figure 1. Dimple Effects on Golf Ball

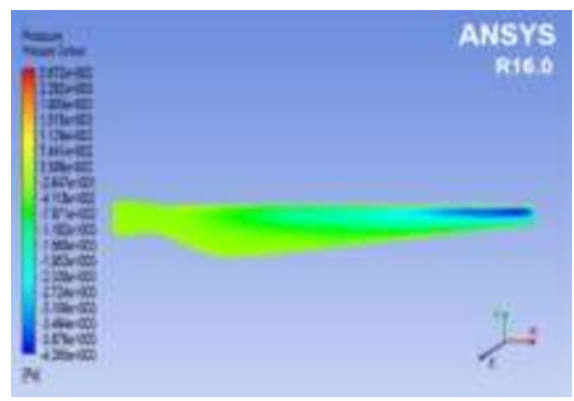

Figure 2. Pressure of Plain Blade Top View 


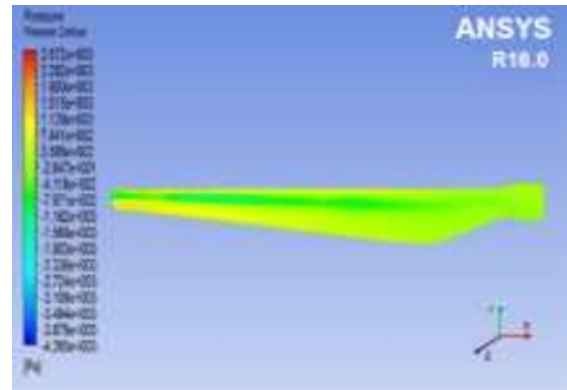

Figure 3. Pressure of Plain Blade Bottom View

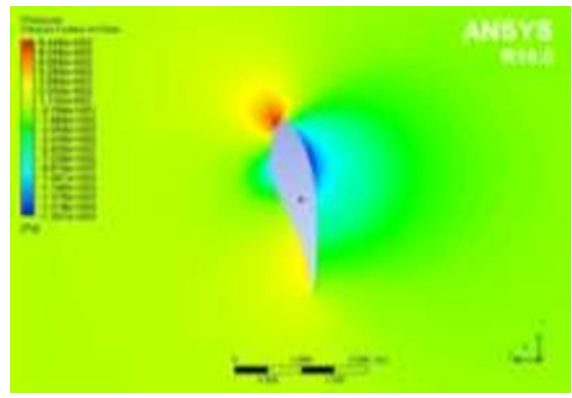

Figure 4. Pressure of Plain Blade Cross Section

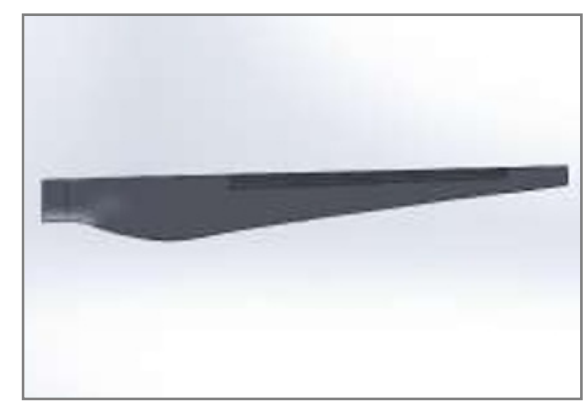

Figure 5. Design of Modified Blade with Dimples

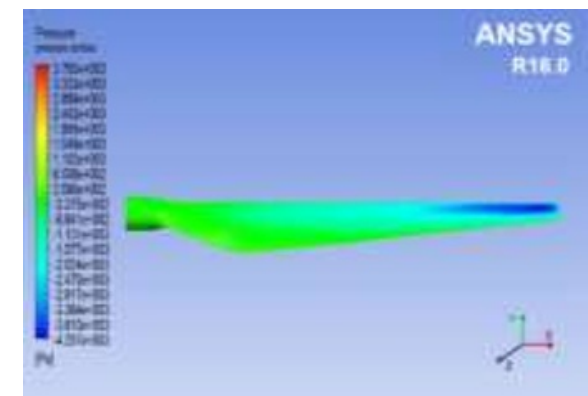

Figure 6. Pressure of Dimpled Blade Top View

After the dimples have been included in the design of the blade, it is then analyzed with the above mentioned settings and the following results are obtained. The pressure contour of the top side of the dimpled blade is shown in the Figure 6 which shows that the low pressure that is created at the top surface of this blade is similar to that of the plain blade. This implies that there is no effect of the dimples on the pressures of the top surface. The pressure contour of the bottom side of the dimpled blade is shown in the Figure 7.

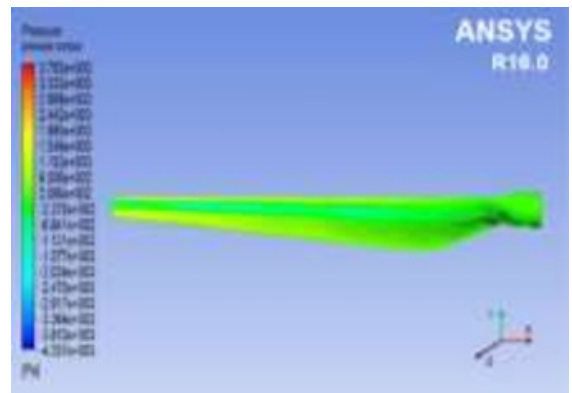

Figure 7. Dimpled Blade Pressure Bottom View

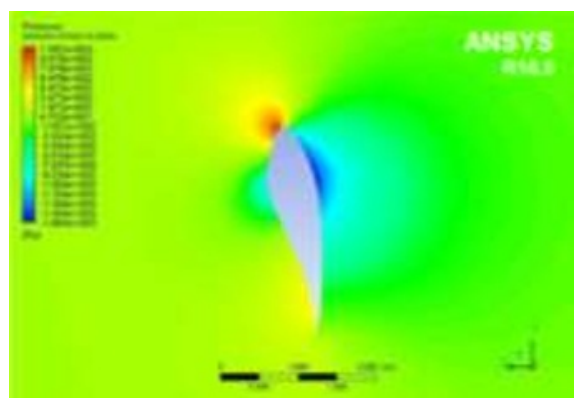

Figure 8. Dimpled Blade Pressure Cross Section

The pressure developed at the bottom is significantly higher when compared to that of the top side of the blade. This high pressure region however is much lesser compared to the plain blade at the region where the dimples have been placed. This indicates that the dimples have effectively reduced the pressure in the region by creating turbulence and hence reduced the drag. By comparing the pressure contour of the cross-section of the dimpled blade as shown in Figure 8 to that of the plain blade, it is seen that the highest pressure as described in the legends have a negligible difference but the region of high pressure is significantly larger in the plain blade. This implies that due to a smaller region of high pressure, the drag in dimpled blades is lesser.

\subsection{Analysis of Torque and Power}

The torque produced by the wind turbine is calculated by means of the function calculator of ANSYS R16.0 CFD post. Only the torque produced by the blade is calculated about the global z-axis as it is the defined axis of rotation in this model. For the plain blade, the torque produced by single blade is found to be $258895 \mathrm{Nm}$ and so the torque produced by the turbine is $776715 \mathrm{Nm}$ which can be converted to power using the formula,

$$
\mathrm{P}=2 \pi \mathrm{NT} / 60 \text {, }
$$

Where, $\mathrm{P}$ is the power, $\mathrm{N}$ is the seed of rotation in rpm and $\mathrm{T}$ is the torque produced

The power is thus found to be $1.70 \mathrm{MW}$ and this power is transmitted to the generator and during the transmission about $20 \%$ loss occurs. This makes a power of $1.36 \mathrm{MW}$ to the generator which is much closer to the actual value. For the dimpled blade the torque produced by single blade is found to be $296615 \mathrm{Nm}$ and so the torque produced by the 
turbine is $890054 \mathrm{Nm}$ which when converted to power is 1.9 MW. After the transmission loss the power available to the generator is about $1.5 \mathrm{MW}$. While comparing the power outputs, it is inferred that there is about $15 \%$ increase of power in dimpled blade turbine when compared to the plain blade turbine.

\section{Conclusions}

The above study on wind turbine blade designed with dimples was done for reducing the air drag in order to increase the efficiency of the blades. From the results the following conclusions were arrived.

- The numerical investigation focused on the aerodynamic effects contributing to torque which eventually improved the performance levels due to the inclusion of dimples.

- The S-series blade profile was chosen for optimum performance of generating a target of $1.5 \mathrm{MW}$ power under wind speed range of $12-20 \mathrm{~m} / \mathrm{s}$ by combining three profiles together.

- The combination proved to have more strength and was found to be thick using actuator disc method without any modifications on the surface.

- Nearly about 1.4 MW power was found to be generated when the dimples were included which is a good level of accuracy when compared with actual value.

- The results showed an increase in power and also $15 \%$ increase in efficiency with the addition of dimples on the surface of wind turbine blades.

\section{References}

[1] Lin Wang et al., State of the art in the Aeroelasticity of wind turbine blades: Aeroelastic modelling, Renewable and Sustainable Energy Reviews, 64, 195-210, (2016).

[2] S. Nallusamy, Thermal conductivity analysis and characterization of copper oxide nanofluids through different techniques, Journal of Nano Research, 40, 105-112, (2016).

[3] Suman Kumar Jha, S. Nallusamy and Sinha Akshat Diwakar, Future energy scenario in India - An essential overview, Pollution Research, 35(3), 595599, (2016).

[4] S. Nallusamy, et al., Analysis of design features for inspection robot make use of concrete structures-An assessment, International Journal of Engineering Research in Africa, 17, 74-81, (2015).

[5] S. Nallusamy, Characterization of epoxy composites with $\mathrm{TiO}_{2}$ additives and E-glass fibers as reinforcement agent, Journal of Nano Research, 40, 99-104, (2016).

[6] Mohamed Khaled et al., Aerodynamic design and blade angle analysis of a small horizontal-axis wind turbine, American Journal of Modern Energy, 3(2), 23-37, (2017).
[7] S. Nallusamy and N. Manikanda Prabu, Heat transfer enhancement analysis of $\mathrm{Al}_{2} \mathrm{O}_{3}$-water nanofluid through parallel and counter flow in shell and tube heat exchangers, International Journal of Nanoscience, 16(5\&6), 01-07, (2017).

[8] S. Nallusamy and A. Karthikeyan, Synthesis and wear characterization of reinforced glass fiber polymer composites with epoxy resin using granite powder, Journal of Nano Research, 49, 01-09, (2017).

[9] Karthikeyan and S. Nallusamy, Experimental analysis on sliding wear behaviour of aluminium6063 with $\mathrm{SiC}$ particulate composites, International Journal of Engineering Research in Africa, 31, 36-43, (2017).

[10] S. Nallusamy and G. Majumdar, Enhancement of overall equipment effectiveness using total productive maintenance in a manufacturing industry, Int. J. of Per. Engg., 13(2), 01-16, (2017).

[11] S. Nallusamy, Productivity enhancement in a small scale manufacturing unit through proposed line balancing and cellular layout, Int. Journal of Performability Engg., 12(6), 523-534, (2016).

[12] Murtagh, Basu and Broderick, Along-wind response of a wind turbine tower with blade coupling subjected to rotationally sampled wind loading, Engineering Structures, 27, 1209-1219, (2005).

[13] S. Nallusamy and Saravanan, Enhancement of overall output in a small scale industry through VSM, line balancing and work standardization, Int. J. of Engg. Res. in Africa, 26, 176-183, (2016).

[14] S. Nallusamy, Efficiency enhancement in CNC industry using value stream mapping, work standardization and line balancing, Int. Journal of Performability Engg., 12(5), 413-422, (2016).

[15] Suman Kumar Jha, S. Nallusamy and Sinha Akshat Diwakar, Future energy scenario in India-An essential overview, Pollution Research, 35(3), 595599, (2016).

[16] S. Nallusamy, Enhancement of productivity and efficiency of CNC machines in a small scale industry using total productive maintenance, Int. J. of Engg. Res. in Africa, 25, 119-126, (2016).

[17] Weijun Tian et al., Bionic design of wind turbine blade based on long-eared owl's airfoil, Applied Bionics Biomechanics, 2017, DOI: 10.1155/2017/8504638, (2017).

[18] S. Nallusamy, Manoj Babu and N. M. Prabu, Investigation on carbon nanotubes over review on other heat transfer nano fluids, Int. Journal of Applied Engg. Research, 10(62), 112- 117, (2015).

[19] S. Nallusamy, M.R. Narayanan and J. Logeshwaran, Synthesis and machining characterization of coppermultiwalled carbon nanotubes-graphene hybrid composite using SEM and ANOVA, Journal of Nano Research, 50, 105-115, (2017). 
[20] Xin Jin et al., Investigation into parameter influence of upstream deflector on vertical axis wind turbines output power via 3-dimensional CFD simulation, Renewable Energy, 115, 41-53, (2018).

[21] S. Nallusamy et al., Reliability analysis of passenger transport vehicles in public sector undertaking, International Journal of Applied Engineering Research, 10(68), 843-850, (2015).

[22] S. Nallusamy, A proposed model for sustaining quality assurance using TQM practices in small and medium scale industries, Int. Journal of Engineering Research in Africa, 22, 184-190, (2016).

[23] Xinzi Tang et al., A direct approach of design optimization for small horizontal axis wind turbine blades, Procedia CIRP, 36, 12-16, (2015).

[24] S. Nallusamy and Adil Ahamed, Implementation of lean tools in an automotive industry for productivity enhancement - A case study, Int. J. of Engg. Research in Africa, 29, 175-185, (2017).

[25] S. Nallusamy, Frequency analysis of lean manufacturing system by different critical issues in Indian automotive industries, Int. Journal of Engineering Research in Africa, 23, 181-187, (2016).

[26] P J. Schubel and Crossley, Wind turbine blade design, Energies, 5, 3425-3449, (2012).

[27] S. Nallusamy, A review on the effects of casting quality, microstructure and mechanical properties of cast Al-Si-O.3Mg alloy, Int. Journal of Performability Engg., 12(2), 143-154, (2016).

[28] S. Nallusamy and A. Karthikeyan, Analysis of wear resistance, cracks and frictional properties of metal matrix composites with $\mathrm{SiC}$ additives and $\mathrm{Al} 2 \mathrm{O} 3$ as reinforcement, Indian Journal of Science and Technology, 9(35), 01-06, (2016).

[29] Okulov et al., Experimental investigation of the wake behind a model of wind turbine in a water flume, J. of Physics, Conference Series, 555, DOI: 10.1088/1742-6596/555/1/012080, (2014).

[30] S. Nallusamy, Analysis of MRR and TWR on OHNS die steel with different electrodes using electrical discharge machining, International Journal of Engineering Research in Africa, 22, 112-120, (2016).

[31] Galih Bangga et al., CFD studies on rotational augmentation at the inboard sections of a $10 \mathrm{MW}$ wind turbine rotor, Journal of Renewable and Sustainable Energy, 9(2), 676-681, (2017).

[32] S. Nallusamy, et al., Analysis of static stress in an alloy wheel of the passenger car, International Journal of Engineering Research in Africa, 16, 17-25, (2015).

[33] S. Nallusamy and G. Majumdar, Effect of stacking sequence and hybridization on mechanical properties of jute-glass fiber composites, Int. Journal of Performability Engg., 12(3), 229-239, (2016).

[34] Nikolaos Simisiroglou, Simon-Philippe Breton and Stefan Ivanell, Validation of the actuator disc approach using small scale model wind turbines, Journal of Physics, 753, 01-10, (2016).

[35] S. Nallusamy, Analysis of welding properties in FSW aluminium 6351 alloy plates added with silicon carbide particles, Int. Journal of Engineering Research in Africa, 21, 110-117, (2015).

[36] S. Nallusamy, Characterization of $\mathrm{Al}_{2} \mathrm{O}_{3} /$ water nanofluid through shell and tube heat exchangers over parallel and counter flow, Journal of Nano Research, 45, 155-163, (2017).

[37] M. Rajaram Narayanan and S. Nallusamy, An experimental analysis of aluminium alloy with tungsten carbide metal matrix composite through insitu method using SEM, Rasayan Journal of Chemistry, 11(1), 355-360, (2018).

[38] S. Nallusamy, et al., Experimental analysis on reinforced aluminium metal matrix with boron carbide, graphite and fly ash composites, Rasayan Journal of Chemistry, 10(4), 1368-1373, (2017).

[39] Sarkar and Behera, Wind turbine blade efficiency and power calculation with electrical analogy, International Journal of Scientific and Research Publications, 2(2), 01-05, (2012). 